\title{
Preparation of Recipient Wound Bed by Platelet Rich Plasma for Skin Flaps in Dogs
}

\author{
M. Gokulakrishnan ${ }^{1 *}$, L. Nagarajan ${ }^{2}$ and C. R. Ramani \\ ${ }^{1}$ Department of Clinics, Madras Veterinary College, Tamil Nadu Veterinary and Animal \\ Sciences University, Tamil Nadu, India \\ ${ }^{2}$ Department of Veterinary Surgery and Radiology, Madras Veterinary College, Tamil Nadu \\ Veterinary and Animal Sciences University, Tamil Nadu, India \\ *Corresponding author
}

\section{Keywords}

Platelet rich plasma, recipient wound bed, skin flap, dogs

Article Info

Accepted: 05 February 2020 Available Online: 10 March 2020
Open wound management, until the wound is considered suitable for reconstruction or until it has healed by second intention, has been the treatment of choice for centuries. The aim of wound healing is to promote rapid wound closure and prevent excess scar formation. Application of platelet rich plasma remain a viable option for enhancing the granulation tissue formation and early wound bed preparation before large wounds could be reconstructed with skin flaps. The flaps performed in the present study were flank and elbow rotational flap, transposition flap, caudal superficial epigastric flap, single and bipedicle advancement flaps. The flaps were selected based on the location and site of the wound. Subjective evaluation of wound healing based on the physical observations, clinical photography, wound planimetry studies were evaluated. Additionally, hematological, bacteriological, biochemical, and histopathological evaluation were done for the recipient wound bed and skin flap. A subjective analysis of vascularity of the donor site was performed through Colour flow Doppler ultrasonography. Platelet rich plasma had the supreme advantage as it offered a multiple synergistically working growth factors that promoted mitogenesis of mesenchymal cells at the wound site. Growth factors viz., transforming growth factor-b, platelet derived growth factor and vascular endothelial growth factor were released after platelet degranulation led to fibroblast recruitment, proliferation and matrix remodelling which ultimately leads to good granulation tissue formation and wound healing in the cases.

\section{Introduction}

The aim of wound healing is to promote rapid wound closure and prevent excess scar formation. To stimulate wound healing, a variety of methods have been used, such as the topical application of herbal remedies like Aloevera extract, the use of soft laser, natural honey and electromagnetic pulses (Houghton and Campbell, 1999). Even though good results have been achieved by these methods, the customary approach remains the 
prevention of infection using antibacterial and antiseptic agents, and sometimes hygroscopic powders (Schultz et al., 2005). Skin flaps or free grafts should be considered for larger defects, for which healing by second intention might be prolonged or expensive. Those reconstructive techniques were advisable when wound contracture or a fragile epithelialised scar might occur (Hunt, 1995).

The wound assessment was a complex activity which aimed to collect a large quantity of information to make appropriate decisions for treatment which was the first step in identifying the suitable treatment objectives for the management of wound (Plassmann, 2005). Tracking wound size was an essential part of treatment. The wound's surface area (S) and surface area-to-perimeter $(\mathrm{S} / \mathrm{P})$ ratio were useful to document healing (Mavrovitz and Soontupe, 2009). Routine histopathological evaluation of collagen measurement and staining pattern of wound healing processes were performed by using Hematoxylin and Eosin and Masson's trichrome stains.

Ultrasonography and colour-flow Doppler ultrasonography were relatively easy, noninvasive and inexpensive methods to assess the integrity of the direct cutaneous arteries and could potentially be helpful when planning an axial pattern flap for flap survival in clinical cases as performed in the present study. The aim of the present study was to determine the uptake of skin flap in chronic wounds treated with Platelet Rich Plasma in dogs.

\section{Materials and Methods}

The study was carried out on six dogs that were brought to Madras Veterinary College Teaching Hospital, Chennai with large wound that required skin flaps. The platelet rich plasma was prepared by the Double centrifugation tube. The Activated Platelet Rich Plasma was applied to the wound on $0,3^{\text {rd }}, 7^{\text {th }}$ and $14^{\text {th }}$ day respectively. After proper granulation, appropriate skin flap technique for the wound was decided based on the wound healing parameters (Ojingwa and Isseroff, 2003).The following skin flaps were performed viz., Single pedicle advancement flap, Flank and elbow rotational flap, Transposition flap and caudal superficial epigastric flap.

Subjective evaluation of wound healing based on the physical observations such as colour, odour and presence of exudates for recipient wound bed and skin flap respectively were performed (Table-1). Clinical Photography, Wound Planimetry studies were evaluated. Additionally biochemical, and histopathological evaluation were done for the recipient wound bed and skin flap. The total protein content from wet granulated tissue samples were performed as per standard protocol.

A subjective analysis of vascularity of the donor site was performed through Colour flow Doppler ultrasonography. After reconstructive surgery, skin flap vascularity and uptake were analysed by the same procedure on $3^{\text {rd }}, 7^{\text {th }}$ and $14^{\text {th }}$ day respectively. The procedure was repeated post operatively to assess the cutaneous arteries on the skin flap on $3^{\text {rd }}, 7^{\text {th }}$, $14^{\text {th }}$ day.

\section{Results and Discussion}

The wound planimetry studies of the recipient wound bed are presented in Table-2.The percentage of epithelisation, contraction and wound healing of recipient wound bed treated by Platelet Rich Plasma are presented in Table-3.

The percentage of epithelisation, contraction and wound healing on $0,3^{\text {rd }}, 7$ th and $14^{\text {th }}$ day 
prior to skin flap, revealed a statistically significant increase. There was significant increase in epithelisation, contraction and wound healing on $3^{\text {rd }}, 7^{\text {th }}$ and $14^{\text {th }}$ day respectively. The slight red colour of wound bed on 3rd day might be due to growth factors that enhanced hemostasis, angiogenesis, growth, vascular fibroblast proliferation by activated platelet rich plasma.

Bright shiny red colour of the open wound was due to micro vascular network throughout the granulation tissue with neo-vascularisation the early neo-vascularisation and granulation as observed by Pavletic (2003). In the present study, the colour of skin flap on 3rd day was predominantly pink, portions of the flap passed from red to pink overtime without necrosis. Colour changes in the early stages of circulatory obstruction could have been due to various reasons as opined by Slatter (2003).

The Platelet Rich Plasma after activation released chemotactic and mitogenic growth factors important in the phase of wound healing (Arguelles et al., 2006). Vasoendothelial, Transforming and Fibroblast growth factors stimulated endothelial growth and promoted angiogenesis, while enhancing capillary permeability and leakage of tissue plasma into the tissue space as reported by Raul et al., (2007).

Bi pedicle advancement flap were performed in one case with wound on the upper eyelid. Transposition flap were performed in one case which had chronic wounds in the left lateral thorax .The Elbow rotational and flank fold flap were performed in one case each respectively.

Caudal epigastric flap was performed in one case. Although the skin was considered as a potential "donor" area for wound closure, the closed donor site was more prone to dehiscence in an active pet but proper immobilisation technique and rest prevented the above complications in the study. In view of the fact that $100 \%$ flap survival occurred in single pedicle and transposition flap but caudal epigastric flap showed survival of at least as good, if not better, than the other result. Vessel kinking and shortening through rotation and transposition become major obstacles when these types of flaps are rotated more than 90 degrees which was considered as precautionary step when transposition flap was done (Connery and Bellenger, 2002).

The mean \pm S.E. values of total protein of granulation tissue showed a significant increase $(\mathrm{P}<0.05)$ in total protein content in granulation tissue on $3^{\text {rd }}, 7^{\text {th }}$ and $14^{\text {th }}$ day. The mean \pm S.E. values for collagen proliferation, epithelisation and angiogenesis was $2.28 \pm$ $0.83,2.38 \pm 0.72,2.40 \pm 0.62$ and $1.80 \pm 0.78$, $2.47 \pm 0.62,2.99 \pm 0.00$ and $2.50 \pm 0.91,2.53$ $\pm 0.63,2.67 \pm 0.12$ on $3^{\text {rd }}, 7^{\text {th }}$ and $14^{\text {th }}$ day respectively.

The degree of confidence in locating cutaneous artery was subjectively graded as high, moderate, or low. A high level of confidence was observed for vessel that was located within 1 to 3 minutes and that its identity was not questioned on donor site viz., scapula, paralumbar, sacral, thorax and flank. A moderate level of confidence was observed for vessel that was located within 3 to 5 minutes on donor site viz.,parascrotal, axilla.

A low level of confidence (> 5 minutes) was not encountered in the study on the donor sites. Growth factors viz., transforming growth factor-b, platelet derived growth factor and vascular endothelial growth factor were released after platelet degranulation led to fibroblast recruitment, proliferation and matrix remodeling and ultimately good granulation Thus, it was important to assess the integrity of the cutaneous vessels before constructing an axial pattern and a subdermal plexus flap to reconstruct a traumatic wound. 
Table.1 Clinical wound cases treated by Platelet Rich Plasma

\begin{tabular}{|c|c|c|c|c|c|c|c|}
\hline \multirow[t]{2}{*}{ Parameters } & \multirow[t]{2}{*}{ Days } & \multicolumn{6}{|c|}{ Dogs } \\
\hline & & 1 & 2 & 3 & 4 & 5 & 6 \\
\hline \multirow[t]{4}{*}{ Colour of open wound } & Day 0 & B & $\mathrm{Y}$ & $\mathrm{Y}$ & $\mathrm{Y}$ & Y & $\mathrm{B}$ \\
\hline & Day 3 & $\mathrm{Y}$ & SR & SR & SR & SR & $\mathrm{Y}$ \\
\hline & Day 7 & SR & $\mathrm{R}$ & $\mathrm{R}$ & $\mathrm{R}$ & $\mathrm{R}$ & SR \\
\hline & Day 14 & $\mathrm{R}$ & $\mathrm{R}$ & $\mathrm{R}$ & $\mathrm{R}$ & $\mathrm{R}$ & $\mathrm{R}$ \\
\hline \multirow[t]{3}{*}{ Colour of skin flap } & Day 3 & $\mathrm{P}$ & $\mathrm{P}$ & $\mathrm{P}$ & $\mathrm{P}$ & $\mathrm{P}$ & $\mathrm{B}$ \\
\hline & Day 7 & $\mathrm{P}$ & $\mathrm{P}$ & $\mathrm{P}$ & $\mathrm{P}$ & $\mathrm{P}$ & $\mathrm{P}$ \\
\hline & Day 14 & $\mathrm{P}$ & $\mathrm{P}$ & $\mathrm{P}$ & $\mathrm{P}$ & $\mathrm{P}$ & $\mathrm{P}$ \\
\hline \multirow[t]{4}{*}{ Odour of open wound } & Day 0 & $\mathrm{O}$ & $\mathrm{P}$ & $\mathrm{P}$ & $\mathrm{P}$ & $\mathrm{O}$ & $\mathrm{O}$ \\
\hline & Day 3 & M & $\mathrm{M}$ & M & $\mathrm{M}$ & $\mathrm{M}$ & M \\
\hline & Day 7 & M & $\mathrm{N}$ & $\mathrm{N}$ & $\mathrm{N}$ & $\mathrm{N}$ & M \\
\hline & Day 14 & $\mathrm{~N}$ & $\mathrm{~N}$ & $\mathrm{~N}$ & $\mathrm{~N}$ & $\mathrm{~N}$ & $\mathrm{~N}$ \\
\hline \multirow{4}{*}{$\begin{array}{l}\text { Odour of flap } \\
\text { Exudate of open wound }\end{array}$} & Day 3 & $\mathrm{~N}$ & $\mathrm{M}$ & M & M & $\mathrm{M}$ & M \\
\hline & Day 7 & $\mathrm{~N}$ & $\mathrm{M}$ & $\mathrm{N}$ & M & $\mathrm{N}$ & M \\
\hline & Day 14 & $\mathrm{~N}$ & $\mathrm{~N}$ & $\mathrm{~N}$ & $\mathrm{~N}$ & $\mathrm{~N}$ & $\mathrm{~N}$ \\
\hline & Day 0 & $\mathrm{E}$ & $\mathrm{E}$ & $\mathrm{E}$ & $\mathrm{E}$ & $\mathrm{E}$ & $\mathrm{E}$ \\
\hline \multirow[t]{4}{*}{ Exudate of the flap } & Day 3 & $\mathrm{E}$ & $\mathrm{E}$ & $\mathrm{E}$ & $\mathrm{E}$ & $\mathrm{E}$ & $\mathrm{E}$ \\
\hline & Day 7 & $\mathrm{ME}$ & ME & $\mathrm{ME}$ & $\mathrm{ME}$ & $\mathrm{ME}$ & $\mathrm{E}$ \\
\hline & Day 14 & $\mathrm{~N}$ & $\mathrm{~N}$ & $\mathrm{~N}$ & $\mathrm{~N}$ & $\mathrm{~N}$ & $\mathrm{ME}$ \\
\hline & Day 3 & $\mathrm{ME}$ & $\mathrm{N}$ & $\mathrm{N}$ & $\mathrm{N}$ & $\mathrm{N}$ & $\mathrm{N}$ \\
\hline
\end{tabular}

B-Black, Y- Yellow, SR-Slight red, P-Pink, O-Offensive, P-Putrid, M-Malodor, N-no abnormality, E- exudative , ME-mild exudative
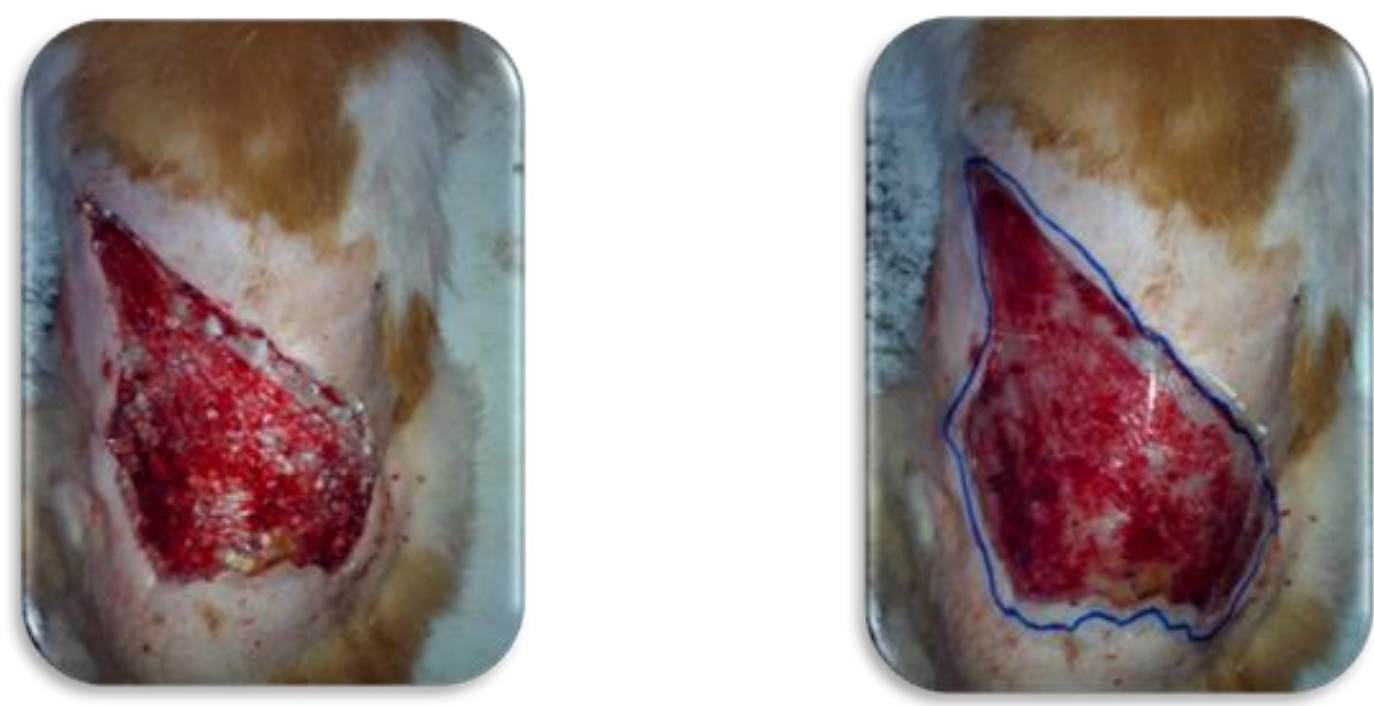

Fig.1 Wound Planimetry drawing of open wound margin on a transparent sheet 
Table.2 Wound planimetry studies of the recipient wound bed

\begin{tabular}{|c|c|c|c|c|c|}
\hline \multirow[t]{2}{*}{ Case No. } & \multirow[t]{2}{*}{ Characteristics } & \multicolumn{4}{|c|}{ Wound Healing \% } \\
\hline & & Day 0 & Day 3 & Day 7 & Day 14 \\
\hline \multirow{3}{*}{1} & Epithelisation & 24.54 & 24.36 & 36.58 & 49.65 \\
\hline & Contraction & 25.34 & 25.69 & 36.23 & 50.26 \\
\hline & Wound Healing & 24.12 & 26.59 & 36.58 & 55.36 \\
\hline \multirow{3}{*}{2} & Epithelisation & 22.87 & 22.54 & 36.00 & 51.26 \\
\hline & Contraction & 25.21 & 23.56 & 36.50 & 51.69 \\
\hline & Wound Healing & 23.54 & 27.45 & 37.02 & 57.96 \\
\hline \multirow{3}{*}{3} & Epithelisation & 20.31 & 24.99 & 35.89 & 52.69 \\
\hline & Contraction & 24.25 & 25.98 & 37.78 & 54.36 \\
\hline & Wound Healing & 24.36 & 25.44 & 34.65 & 51.26 \\
\hline \multirow{3}{*}{4} & Epithelisation & 21.36 & 23.89 & 35.68 & 49.56 \\
\hline & Contraction & 22.99 & 24.98 & 36.99 & 52.31 \\
\hline & Wound Healing & 24.12 & 27.89 & 38.54 & 55.05 \\
\hline \multirow{3}{*}{5} & Epithelisation & 23.24 & 26.00 & 36.99 & 52.69 \\
\hline & Contraction & 25.48 & 26.54 & 39.23 & 56.98 \\
\hline & Wound Healing & 25.36 & 27.99 & 38.99 & 55.99 \\
\hline \multirow{3}{*}{6} & Epithelisation & 25.14 & 27.56 & 36.15 & 54.68 \\
\hline & Contraction & 23.47 & 28.00 & 39.99 & 57.00 \\
\hline & Wound Healing & 26.54 & 26.54 & 36.54 & 55.02 \\
\hline
\end{tabular}

Table.3 Percentage of wound epithelisation, Contraction and Wound healing of recipient wound bed of different Groups (Mean \pm SE)

\begin{tabular}{|r|c|c|c|c|}
\hline \multirow{2}{*}{ Cases/Days } & \multicolumn{4}{|c|}{ Wound epithelisation } \\
\cline { 2 - 4 } & $\mathbf{0}$ Day & $\mathbf{3}^{\text {rd }}$ Day & $\mathbf{7}^{\text {th }}$ Day & $\mathbf{1 4}^{\text {th }}$ Day \\
\hline $\mathbf{1}$ to 6 & $23.91 \pm 0.75^{*}$ & $24.89 \pm 0.71^{*}$ & $36.22 \pm 0.20^{* *}$ & $51.76 \pm 0.81^{* *}$ \\
\hline \multirow{2}{*}{$\mathbf{1}$ to 6 } & $24.47 \pm 0.44^{*}$ & $25.76 \pm 0.61^{*}$ & $37.79 \pm 0.20^{* *}$ & $53.77 \pm 0.15^{* *}$ \\
\hline & & Wound contraction \\
\hline & & Wound healing \\
\hline
\end{tabular}

Means bearing in rows and columns vary significantly $(* \mathrm{P}<0.05)$ or $(* * \mathrm{P}<0.0$ 


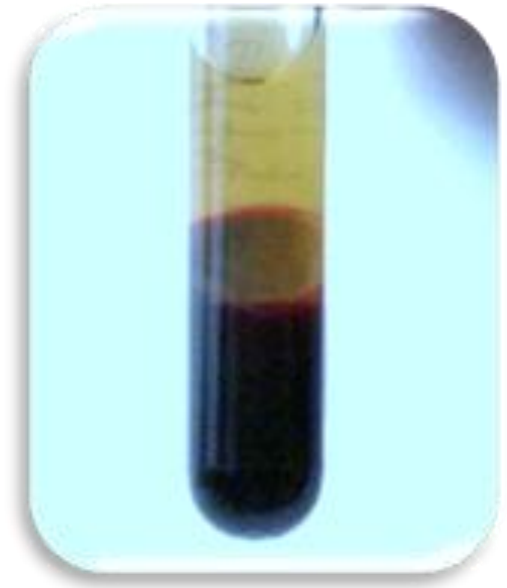

Fig.2 Buffy Coat (Mononuclear cell and Platelets)

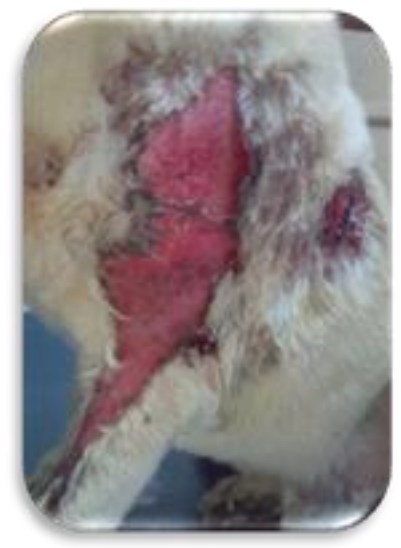

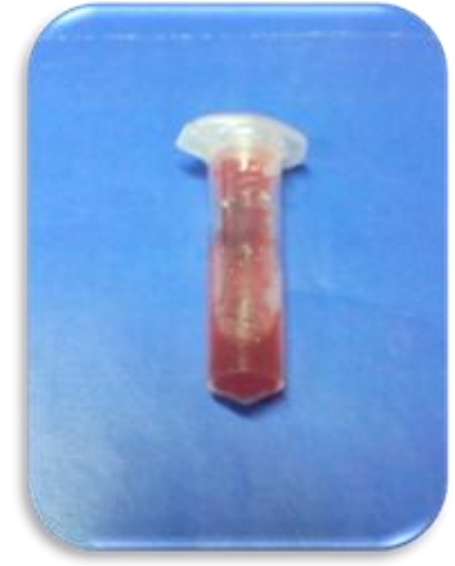

Fig.3 Eppendorf vial with PRP

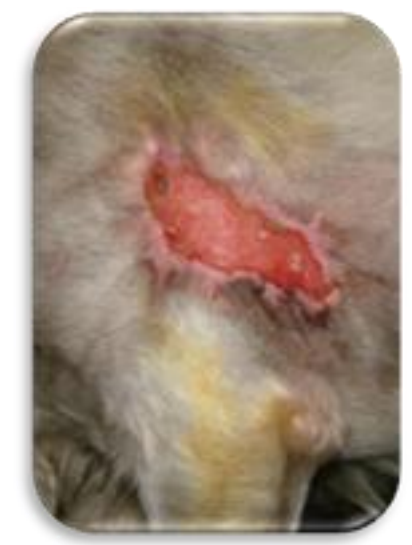

Fig.4\&5 Clinical observation of recipient wound bed of animals treated by Platelet Rich Plasma
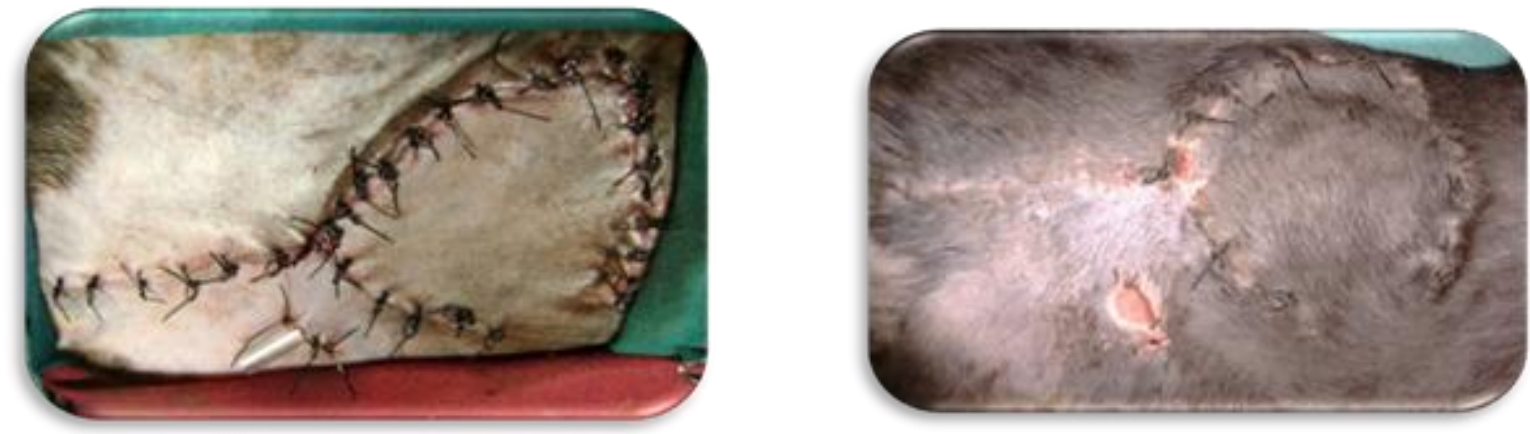

Fig.6\&7 Clinical observation of skin flap of animal (Transposition Flap)

Because of relatively small diameter of these vessels and their superficial location, 10 to $12 \mathrm{MHz}$ linear transducer was best for obtaining diagnostic information. A low level of confidence (> 5 minutes) was not encountered in the study on the donor sites. This might be due to the selection of established donor sites and better perfusion in areas adjacent to the flap designed by subdermal plexus and collateral blood vessels 
(Reetz et al., 2006). The mean \pm S.E. values of Whole Blood Platelet count in animals on 0 , 3rd, 7th, 14th which were $388975 \pm 0.43$, $396587 \pm 0.44,402358 \pm 0.44$ and $412356 \pm$ 0.35 respectively. The mean \pm S.E. values of platelet rich plasma in animals on $0,3 \mathrm{rd}, 7 \mathrm{th}$, 14 th were $1517003 \pm 0.52,1578416 \pm 0.52$, $1609432 \pm 0.52$ and $1608188 \pm 0.89$ respectively. The Platelet value for whole blood in the treatment Group III on 0, 3rd, 7th and 14th day did not reveal statistically significant difference $(\mathrm{P}<0.05)$ within them. But there was a highly significant difference between the whole blood platelet count and the platelet rich plasma count $(\mathrm{P}<0.01)$ on 0 , 3 rd, 7th and 14th day.

PRP must contain a higher concentration of platelets than baseline; however an increase in platelets was a very gross description of Platelet rich plasma. Several parameters were taken into account in the present study when considering Platelet rich plasma that included platelet concentration above baseline, whether or not leucocytes were included, whether or not the PRP had been anticoagulated and whether it required exogenous activation. The protocol used for platelet activation in the present study included the use of a calcium salt solely.

To date, there is no convincing data about what is the best activating substance (in terms of GF concentration) for PC activation and more research is necessary to know the effect of these substances (either alone or combined) on the release of platelet main derived GF. (Lorenzo et al., 2013).Platelets played a central role in the healing process not only due to hemostatic properties but also by proinflammatory, regulatory and regenerative properties, which were mediated by interaction with other cells (neutrophils and endothelial cells), GF, Chemokines and other rregulatory molecules (Mannaioni et al., 2004 and Anitua et al., 2004). Angiogenesis and
Fibroplasia was higher on the recipient wound bed and skin flap. Platelet rich plasma had the supreme advantage when compared to a single recombinant growth factor as it offered a multiple synergistically working growth factors that promoted mitogenesis of mesenchymal cells at the wound site (Arguelles et al., 2006).

Hence, in the present study, Platelet rich plasma enhanced hemostasis, reepithelisation, angiogenesis, growth, and vascular fibroblast proliferation, increased extracellular collagen matrix synthesis and deposition which leads to overall increas in the survival rate of the skin flap.

\section{Acknowledgement}

The authors acknowledge the Dean, Madras Veterinary College and Director of Clinics, Madras Veterinary College Teaching Hospital for providing necessary support to carry out this project.

\section{References}

Anitua, E., Andia, I., Ardanza, B., Nurden, P. and Nurden, A.T. 2004. Autologous platelets as a source of proteins for healing and tissue regeneration. ThrombHaemost. 91:4-15.

Arguelles, D., Carmona, J.U., Pastor, J., Iborra, A., Viñals, L., Martínez, P., Bach, E. and Prades, M. 2006. Evaluation of single and double centrifugation tube methods for concentrating equine platelets. Res Vet Sci.81:237-245.

Connery, N.A. and Bellenger, C.R. (2002). Surgical management of haemangiopericytoma involving the biceps femoris muscle in four dogs. Journal of Small Animal Practice. 43, 497-500.

Houghton, P. E. and Campbell, K. E. 1999. 
Choosing an adjunctive therapy for the treatment of chronic wounds. Ostomy Wound Management. 45: 43-52.

Hunt, G., Geraldine, B., Penelope, L.C., Julius, M., Liptak. and Richard, M. 2001. Skin Fold Advancement Flaps for Closing Large Proximal Limb and trunk defects in dogs and cats.veterinary surgery. 30:440-448.

Iacopetti, I., Perazzi, P., Ferrari, V. and Busetto, R. 2011. Application of Platelet-Rich Gel to Enhance Wound Healing in the Horse. a case report. J.Equine. Vet. Sci. 32(3):123-8.

Kilroy, G.E., Foster, S.J., Wu, X., Ruiz, J., Sherwood, S., Heifetz, A., Ludlow, J.W. and Gimble, J.M. 2007. Cytokine profile of human adipose-derived stem cells: expression of angiogenic, hematopoietic, and pro-inflammatory factors. J. Cell. Physio. 212: 702-709.

Lorenzo, D., Monica, B., Christian, V., Silvio, T. and Massimo, D. F. 2013. Antimicrobial activity of pure plateletrich plasma against microorganisms isolated from oral cavity. BMC Microbiology. 13: 47.

Mannaioni, P.F., M.G. Di Bello, and E. Masini. 1997. Platelets and inflammation: role of platelet-derived growth factor, adhesion molecules and histamine. Inflamm. Res. 46:4-18.

Mayrovitz, H.N. and Soontupe, L.B. 2009. Wound areas by computerized planimetry of digital images: accuracy and reliability. Adv. Skin. Wound. Care. 22 (5): 222-9.

Ojingwa, J.C. and Isseroff, R.R. 2003. Electrical stimulation of wound healing. J. Invest. Dermatol. 121 (1):1-12.

Pavletic, M.M. 2003. Skin and Adnexa. Textbook of small animal surgery Ed D. Slatter, Vol.1, 3rd ed, pp 250259.Saunders.philadelphia.

Plassmann, P. 2005. Measuring wounds. J. Wound. Care. 4(6): 269-72.

Raul, F., Jorge, U. and Cleuza, M.F. 2007. Comparison of the effect of calcium gluconate and batroxobin on the release of transforming growth factor beta 1 in canine platelet concentrates.BMC Veterinary Research. 8:212.

Reetz, J.A., Seiler, G., Mayhew, P.D. and Holt, D.E. 2006. Ultrasonographic and color - fl ow Doppler ultrasonographic assessment of direct cutaneous arteries used for axial pattern skin fl aps in dogs. J Am Vet Med Assoc 228: 1361 1366.

Schultz, G., Mozingo, D., Romanelli, M. and Claxton, K. 2005. Wound healing and TIME: new concepts and scientific applications. Wound Repair Regen 13 (4 Suppl): S1-S11

Slatter, D.H. Textbook of Small Animal Surgery. Philadelphia, PA; [Great Britain]: $\quad 2003$.

\section{How to cite this article:}

Gokulakrishnan. M, L. Nagarajan and Ramani. C. R. 2020. Preparation of Recipient Wound Bed by Platelet Rich Plasma for Skin Flaps in Dogs. Int.J.Curr.Microbiol.App.Sci. 9(03): 954961. doi: https://doi.org/10.20546/ijcmas.2020.903.112 